\title{
Reported Relative Value of Journals versus Use: A Comparison
}

\section{Marifran Bustion and Jane Treadwell}

In the fall of 1987 the Sterling C. Evans Library cancelled subscriptions to approximately 1,000 serials that faculty reported as being marginal or irrelevant to instruction and research at Texas AEM University. During the spring semester 1988 a use study of journals received in the Current Periodical department was conducted to determine if patterns of use coincided with reports of relative importance. All cancelled titles received in Current Periodicals were included in the study.

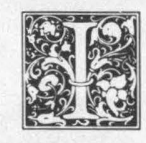

n combination with other collection management reviews, libraries conduct use studies of serials to determine the extent serials are used, the age at which they are no longer useful, which subjects are used more heavily than others, and which titles should be considered core journals in each subject. Results of use studies aid in collection management, development and update of circulation policies, and budget control justification.

In response to the rising costs of serials and a materials budget that was increasingly devoted to serials, the Sterling C. Evans Library at Texas A\&M University conducted a serials review process during the spring of 1987 to determine which serials subscriptions could be cancelled. ${ }^{1} \mathrm{Be}-$ fore the serials review project, serials had not been tracked by subject or department. As a preliminary step to the review process, collection development librarians assigned departments (up to four) to each title. For instance, the title Advances in Electronics and Electron Physics was assigned to the Electrical Engineering, Biochemistry and Biophysics, and Range Science departments. Faculty were then asked to score those titles believed to be of interest to their department. The faculty were also asked to indicate which titles could be cancelled. After scores were returned and reviewed, librarians initiated cancellation proceedings.

Because the cancellations were to be effective with the next calendar year, there was insufficient time to conduct a use study prior to cancellation to determine the relevance of faculty scores to journal use. Public institutions often must make budget reduction decisions quickly and without time to gather all the data that might be desirable to support the decision. The Evans Library's serials review process, conducted without usage data as an element of the cancellation decision, is a case in point.

Although use studies are often conducted as a means of identifying titles to be cancelled or transferred to storage, they are seldom employed to justify budget

Marifran Bustion is Serials Librarian at the Sterling C. Evans Library, Texas AEM University, College Station, Texas 77843-5000. Jane Treadwell is Director of Collection Management in the General Libraries, Emory University, Atlanta, Georgia 30322. The authors express appreciation to Jane Oliver, Molly Blaisdell, and Mary An Richardson for their assistance in this study. 
control. ${ }^{2-4}$ Methods often used to determine the value of specific journals to researchers and students include examination of (1) interlibrary loan requests, (2) circulation statistics, (3) photocopying frequency, (4) citation analyses, (5) user surveys, and (6) use studies. ${ }^{5-8}$ The Evans Library employed the user survey method due to the need for rapid decisions.

After subscription cancellation decisions were made, based on faculty scores, the user survey was conducted to ascertain if current use coincided with faculty reports of relative value. The decision not to use other methods was made based on economic factors and appropriateness to questions considered in this study:

1. Interlibrary loan data can assist in identifying journals to be added to a collection and should be a factor in determining if subscriptions should be ordered. At the time cancellation decisions were made, the Evans Library was not ordering new subscriptions.

2. The library's circulation policy stipulates that periodicals do not circulate. The only exception is a short-term loan of four hours for photocopying. Because of the implementation of this policy, all periodicals that circulate are reshelved upon return with those items used in-house.

3. Users of the Evans Library do their own photocopying. After use, this material is also reshelved with all periodicals used in-house.

4. Citation analysis is useful as an aid in identifying those titles considered core journals in each subject, but was considered prohibitive for this study in terms of cost and time.

\section{PROBLEM STATEMENT}

When academic libraries undertake a serials cancellation project, faculty opinion of the relative importance of journal subscriptions is frequently solicited and considered in the final decision to cancel or retain subscriptions. ${ }^{9}$ This was the case at Texas A\&M, where a major factor in the decision-making process was the determination by the faculty that a journal was either "essential" or "not related" to instruction and research. Those journals rated by the faculty as being not related to research were cancelled; those rated essential, or at least important, were retained.

After decisions were made and subscriptions cancelled, effective January 1988, the head of Resource Development and the Serials Librarian initiated a study to determine if patterns of use coincided with ratings of relative importance.

\section{METHODOLOGY}

During the review, faculty were asked to score titles in their subjects from one (considered essential to research and instruction) to five (not relevant to the department's needs). Figure 1 defines the five scores the faculty used and the two scores collection development librarians used in rating titles not scored by the faculty. (Some faculty refused to participate in the review process. Titles assigned to those departments were later appraised and scored by librarians.)

Journal subscriptions to be cancelled were identified only partly from the ratings of the faculty. Duplicate subscriptions of titles received at the Medical Science Library at Texas A\&M University and most of the titles rated "not related to the department's instruction and research program" were automatically cancelled. Some departments scored only those titles considered essential; others scored only those titles considered essential and those not related to the department's needs; others refused to participate in the review process. A score of six was given to those titles not ranked by appropriate departments and judged, by resource development librarians, to be marginal or not related to the department's needs. Those titles not scored by the faculty but deemed by librarians to be relatively essential were given a score of seven (not ranked) and were retained.

The use study initiated by the Serials Librarian and head of Resource Development was conducted during the spring semester 1988. Reshelving counts of all cancelled periodicals and of a random sample of current periodical titles rated essential (score $=$ one) were compared. The faculty rated 3,000 titles as essential; ap- 
1. Essential for instruction and basic for research in broad areas of the discipline. Students and faculty consult this title regularly.

2. Important for the discipline though less closely related to existing instruction. May be of considerable importance for advanced research but not as broadly applicable to the instruction and research program as item 1 above.

3. Useful but not basic or central to instruction and research programs of the university. May fill individual research needs; these are likely to be highly specialized. (Interlibrary loan access would be satisfactory.)

4. Marginal to the department's instruction and research program and infrequently consulted. May serve occasional research needs; rarely used for instruction. (Interlibrary loan access would be satisfactory.)

5. Not related to the department's instruction and research program; never consulted.

6. Same as 4 or 5 but assigned by the library if a department did not meet its 10 percent goal.

7. Not ranked by either faculty or the library.

FIGURE 1

Rankings for Spring 1987 Serials Review Process

proximately 10 percent (315) were selected to be part of the study. The random sample was chosen from an alphabetic list of the 3,000 titles using a random-number generator. The library cancelled 998 serials subscriptions. Of those, 540 (54 percent) were periodicals. Of the more than 15,000 serials subscriptions, approximately 8,000 are periodicals. Current periodicals, for the purposes of this study, were considered those serials with a publication schedule of more than once a year, with regular numbering, and that were no more than eighteen months old. Monographic series, newspapers, annuals, and other nonperiodical serials were excluded from both groups. The study was not intended to identify further titles for cancellation.

\section{"The library cancelled 998 serials subscriptions. Of those, 540 (54 per- cent) were periodicals."}

Answers to the following questions were sought:

1. Was the use of cancelled journals low enough to warrant cancellation?

2. Did those journals scored essential indicate, by use, their necessity to researchers?

3. Were there variations in use patterns by subject area?

4. Could more use be expected of essential journals prior to indexing than of nonessential titles? That is, if a journal is considered essential, would it be browsed more during the first year of receipt than less-essential journals?

A use study that would have included bound periodicals was beyond the resources of the library in the spring of 1988, since the Shelving Unit of the Circulation Division was involved in a storage project. The investigators were limited to the questions, Are journals that are considered essential consulted during their first year in the library? and Which disciplines engage in browsing of current periodicals?

A file of all serials titles was created using dBase III + as a management tool for the review process. This file was manipulated to allow easy identification of the two groups of titles and to sort in alphabetic and call number order. One list of all titles was in alphabetic order for serials check-in staff to use to mark their paper records with bright orange dots. As issues were received, checkers attached an orange dot to the issue.

Another list was in call number order for staff in the Current Periodicals Depart- 
ment (CPD) to use as they reshelved issues. A log sheet that listed the journal titles in call number order, double-spaced, was forty pages long. Student assistants in the CPD indicated use of each item with tick marks as it was reshelved.

At the end of the semester, all pages were collected and totaled. Data were entered into the $\mathrm{dBase} \mathrm{III}+$ file and exported to Lotus 1-2-3. Data were then manipulated to provide information indicating the number of times each journal title was reshelved.

Prior to the use study, acquisitions staff cancelled the appropriate subscriptions with vendors and publishers. However, internal notification of cancellations was not initiated until after the use study was completed so that patrons and staff were not immediately aware of which subscriptions had been cancelled. There was no announcement, except to those staff directly involved, that a use study was in progress. As one study indicated, signs posted reminding patrons not to reshelve material resulted in a higher patron use rate; ${ }^{10}$ therefore, no signs were posted asking users not to reshelve.
Binding Department staff were instructed not to bind any of the titles in the study until the end of the spring semester. This made available to users at least twelve months of each title.

\section{RESULTS}

The authors had no preconception of what number of uses should constitute low, medium, or high use. A study of the literature revealed that some consider only whether a title received use and set no standard for low, medium, or high use, although Charles Wenger and Judith Childress indicated that 100 uses per title in a six-month period was high use. ${ }^{11-13}$ This figure did not seem comparable to the Evans Library's study for two major reasons:

1. The Evans Library study was limited to current issues, while the Wenger/ Childress study addressed use of back volumes as well as current issues.

2. The number of uses for a given title can be related to the number of persons, whether faculty or student, in that discipline. Use of a library collection in a large university may be different than that in a

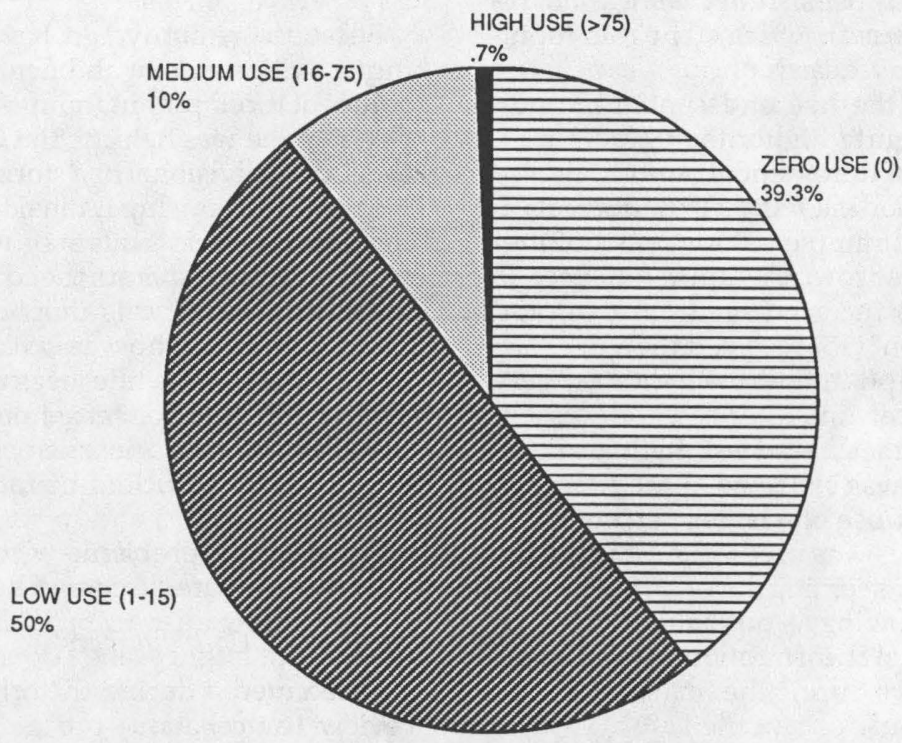

FIGURE 2

Cancelled Titles: Percentage of Use 
small or medium-sized college or university.

For the purposes of this study, low use was arbitrarily defined by the authors as 1 to 15 uses per periodical, medium use as 16 to 75 uses, and high use as more than 75 uses during the fifteen weeks.

Figure 2 shows that 89 percent (482) of the cancelled periodicals received either no or low use, that 10 percent (54) of the cancelled periodicals received medium use, and that less than 1 percent (4) received high use.

"Of the four cancelled periodicals receiving high use, one, Chain Store Age Executive with Shopping Center Age, received 174 uses; the other, Car Craft, received 120 uses."

Of the four cancelled periodicals receiving high use, one, Chain Store Age Executive with Shopping Center Age, received 174 uses; the other, Car Craft, received 120 uses. Chain Store Age was reinstated as it was heavily used and faculty in the Business School requested it not be cancelled after the study began. Car Craft was not reinstated because it was used neither for instruction nor research.

Although the use of essential periodicals was slightly higher, as figure 3 indicates, most of the essential periodicals also received low use. Of the 315 periodicals in the essential sample, 80 percent (252) received zero or low use; approximately 15 percent (47) received medium use, and only 5 percent (15) received high use.

As the graph in figure 4 indicates, very few periodicals in either category, essential or cancelled, received high use. Although this was expected of the cancelled titles, higher use of a larger percentage of essential titles was predicted. Studies discussing this seeming inconsistency suggest the following as possible reasons: ${ }^{14}$

1. Research or instruction in some areas was not active during the time period covered.

2. Reshelving statistics are not an accu- rate indication of use or importance.

3. Some subscriptions are placed for the use of one faculty member knowing they will receive low use.

The average number of uses for essential periodicals was 15 ; for cancelled periodicals, 6 . The median use for essential periodicals was 3 ; for cancelled periodicals, one. Figure 5 lists the titles receiving high use.

Figure 6 compares the average use of titles within each Library of Congress classification. Because of the variable sample size, a comparison between classification is not statistically justified. Although the small sample size studied in a relatively short time span may have biased the results, a few classifications, especially D (History) and $G$ (Geography) suggest heavier use among some cancelled titles than those rated essential. As can be seen in the graph, three of the classifications, A (General), L (Education), and U (Military Science), appear to have had heavier use than the small sample size would suggest. This can be partly explained by class assignments in Education and Military Science and by the popularity of general periodicals.

\section{PROBLEMS: WORK FLOW}

Because the study involved coordinating activities among the Circulation, Resource Development, and Acquisitions Divisions, it was helpful that the heads of the three divisions had formed a good working relationship. A major concern of the Current Periodicals staff was the time necessary for separating, counting, and reshelving periodicals during the study. The supervisor, who was involved in decision making from the beginning of the project, made a concerted effort to train the CPD staff in the necessary procedures, thus ensuring efficient counting and reshelving.

Some minor problems encountered by the CPD staff are discussed below.

\section{Incomplete Call Numbers}

Data entered during the original serials review (cancellation) process listed only the first six characters of each call number. 


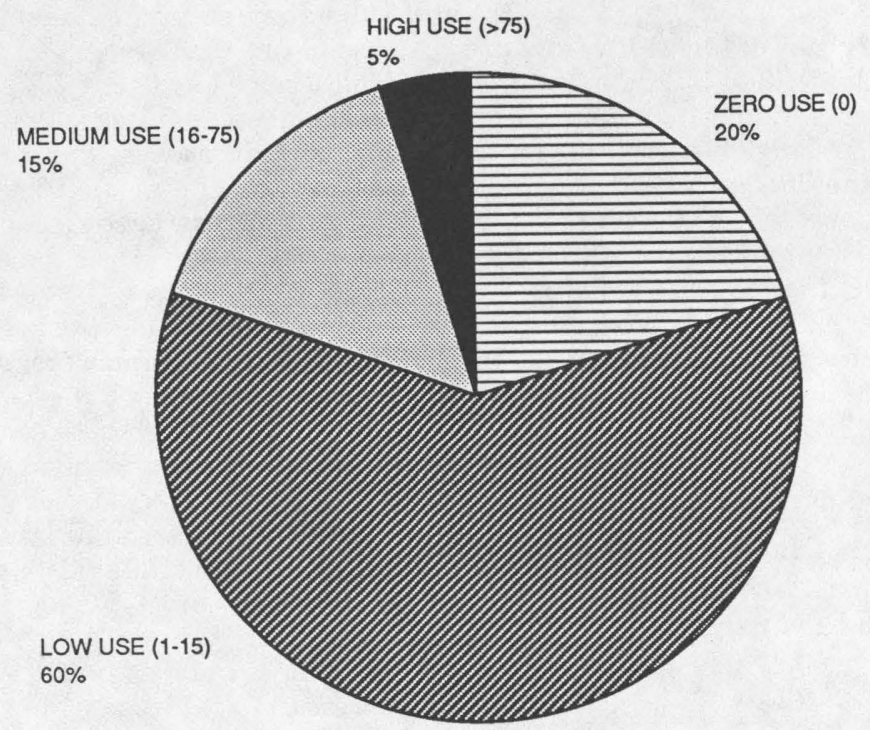

FIGURE 3

Essential Titles: Percentage of Use

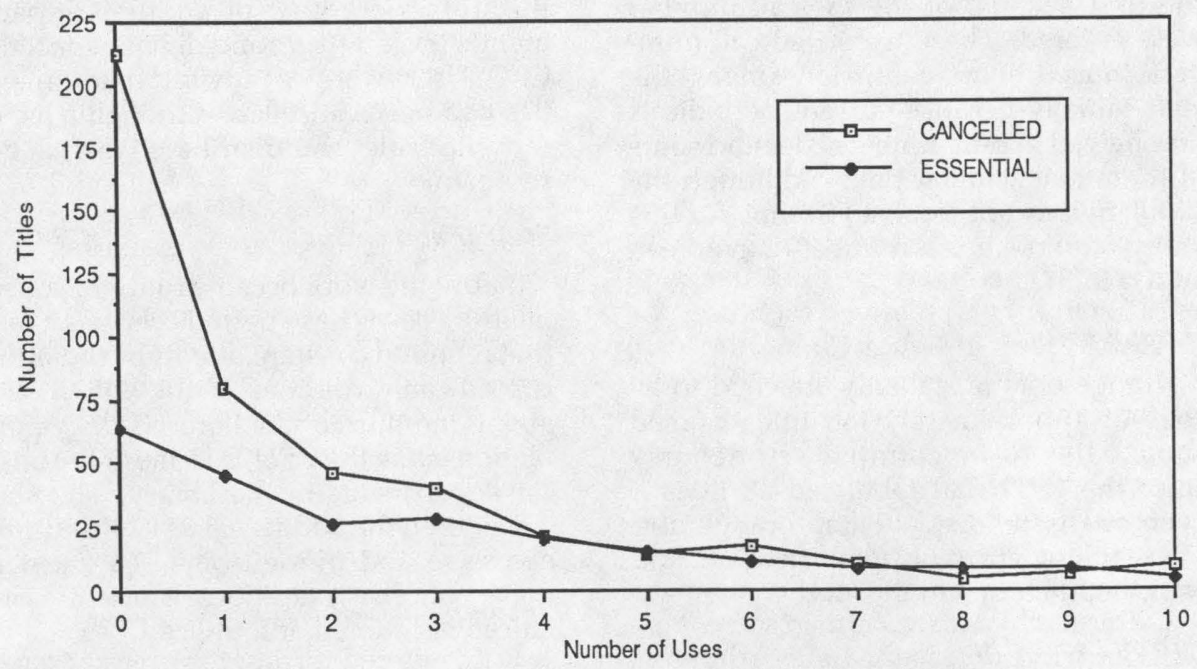

FIGURE 4

Number of Uses: Essential versus Cancelled Titles 


\section{Essential Titles}

\begin{tabular}{cl} 
Number of Reshelvings & Titles \\
85 & Ebony \\
87 & Angewandte Chemie \\
94 & Data Base \\
101 & International Defense Review \\
129 & Commonweal \\
132 & Educational Technology \\
142 & Audio \\
145 & EOS Transactions. American Geophysical Union \\
162 & Exceptional Children \\
210 & Billboard \\
214 & Learning \\
248 & Life \\
274 & Adweek \\
303 & MacLean's \\
349 & Phi Delta Kappan \\
& Cancelled Titles \\
75 & Production \\
93 & Beverage Industry \\
120 & Car Craft \\
174 & Chain Store Age Executive with Shopping Center Age \\
\hline
\end{tabular}

FIGURE 5

Titles Receiving More Than Seventy-five Uses

Neither cutter numbers nor numbers after the first decimal of the LC call number were entered. These truncated call numbers caused some confusion among the staff initially because current periodicals are shelved in call number order and some of them have similar titles. Although the problem was not resolved in time for this study, complete call numbers have been added to the file.

\section{Human Error}

Orange dots mistakenly attached to issues of approximately ten titles caused some titles to be counted erroneously since the CPD staff tabulated all titles if even one issue displayed an orange dot. These titles were easily identified later and were not included in the study.

\section{Patron Curiosity}

Users questioned the purpose of the orange dots. The CPD staff, concerned about giving too much information, devel- oped a general statement that indicated the dots were part of another department's project (true) and did not affect the CPD. Users were not advised that some titles had been cancelled, although a list of cancelled titles was distributed to each department.

\section{Staff Involvement}

Before the work became routine, counting the use of these periodicals was a task that required constant attention and interrupted daily routines of the CPD. With about one-third of the library's daily population using the CPD, it is one of the busiest departments in the library. The staff considered the additional task of counting excessive and burdensome. To alleviate these concerns, additional student assistance was offered and utilized.

\section{PROBLEMS: METHODOLOGY}

When the decision was made to conduct 


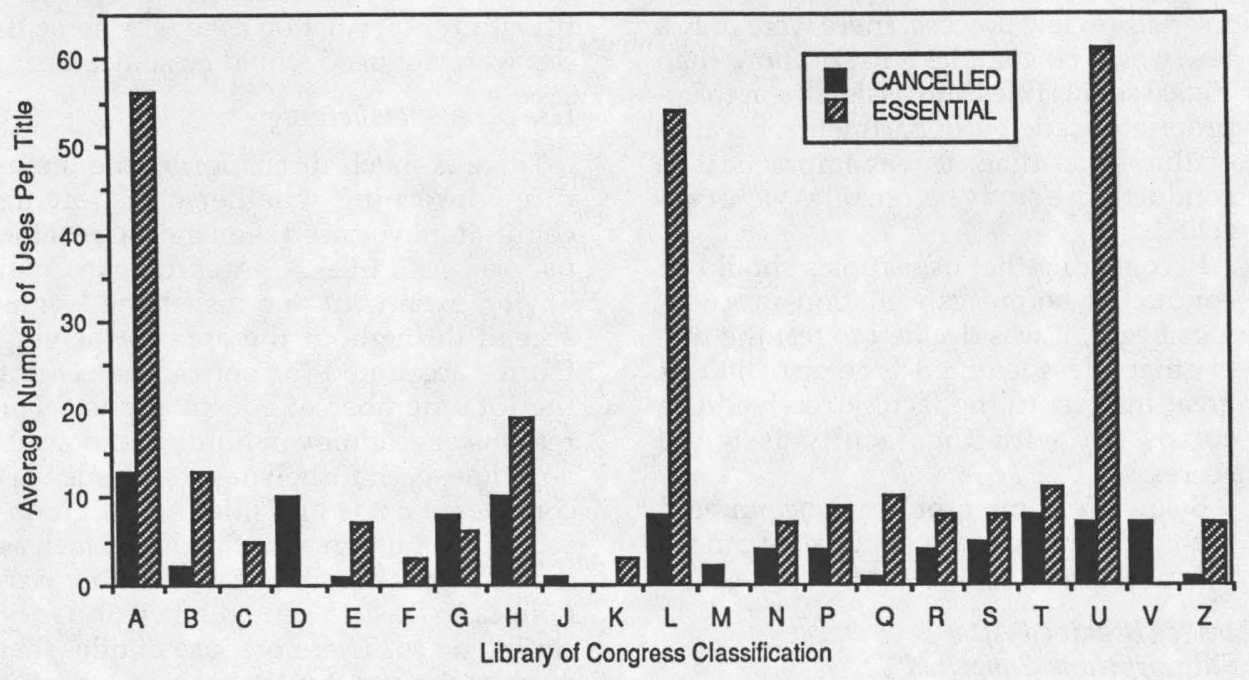

Number of Titles Within Each Classification

$\begin{array}{rr}\text { CLASSIFICATION CANCEUED } & \text { ESSENTIAL } \\ \text { TITLES } & \text { TITLES }\end{array}$

A
B
C
D
E
F
G
H
J
K
L
M
N
P
Q
R
S
T
U
V
Z

$\begin{array}{rr}21 & 15 \\ 2 & 7 \\ 1 & 1 \\ 12 & 5 \\ 6 & 5 \\ 0 & 7 \\ 20 & 8 \\ 87 & 34 \\ 3 & 0 \\ 1 & 1 \\ 5 & 18 \\ 1 & 0 \\ 4 & 6 \\ 12 & 40 \\ 122 & 71 \\ 78 & 5 \\ 40 & 16 \\ 106 & 69 \\ 2 & 2 \\ 2 & 0 \\ 12 & 4\end{array}$

FIGURE 6

Average Number of Uses per Title within Each LC Classification 
a serials review process, there were only a few weeks to compile a list of more than 15,000 serials titles and assign them to appropriate academic departments. Because of this short time, it was impractical to conduct a use study before titles were cancelled.

Recognizing that use studies should be conducted before cancellation proceedings begin, it was decided to test the theory that titles identified as being of little or great interest to the faculty received use consistent with the faculty-assigned scores.

Below are some problems encountered with conducting a use study after cancellation decisions have been made.

\section{Issues Received After \\ Subscriptions Cancelled}

Although most publishers cancelled subscriptions as directed, effective January 1988, some continued เo send issues after the stop date. The library continued to receive issues of approximately 42 percent of the cancelled subscriptions for at least one month after the effective cancellation date. These titles were therefore more accessible to patrons than those for which no issues were received after the cancellation date.

\section{Discouragement Factor}

The library received no issues for most of the cancelled subscriptions after January 1988 . About 17 percent of the cancelled subscriptions were not filled through the end of 1987 because the titles ceased publication, publishers stopped sending issues as soon as they received notification of the cancellation, or there were other problems with subscription agreements. Users first recognized that some issues were unavailable and inquired for them at the service desk. Without easy access to these issues, it was difficult to identify a normal use pattern of these titles.

\section{Use of Older Issues}

Informal observation suggested that some patrons, particularly those not in the sciences, tend to use older volumes of serials rather than current issues. Since only the use of current issues was examined in this study, speculation as to why some titles were not used would be conjecture.

\section{Use versus Reshelving}

There is much discussion in the literature concerning whether a reshelving count should be used as an indicator of the use of specific titles. ${ }^{15-17}$ According to Colin Taylor, even with "no reshelving" signs spread throughout the area, reshelving figures accounted for only 40 percent of the total number of consultations. ${ }^{18}$ For reasons of economy in funding and available time, each reshelving of an issue was considered a use of a title. Although observation of use in a confined area such as the CPD was possible, it was neither economically feasible nor an efficient use of staff to do so. Therefore, use of titles that were reshelved by the patron was not counted.

Reshelving is a continuous operation in the CPD, and the number of patrons actively using the collection is very high. Informal observation suggests more than one user may read an issue before it is reshelved. ${ }^{19}$ Only the number of times each issue was reshelved was considered in the study.

\section{CONCLUSIONS}

In general, the cancellation decisions were reaffirmed, as nearly 40 percent of subscriptions cancelled received no use during the study. Moreover, nearly 50 percent of those cancelled received very low use. Conversely, a high ranking by the faculty did not prove to be a predictor of high use. There appeared to be a very weak relationship between the perceived value of those periodicals scored as essential and the amount of use during the first year of receipt.

The use study conducted at the Sterling C. Evans Library raised additional questions. The lack of use of titles considered essential by the faculty to research and instruction suggests there are other areas to be considered before final conclusions can be reached regarding cancellation of lowuse periodicals. Those with immediate implications to the Evans Library are:

1. If one-third of the user population goes to the CPD but the level of use among 
periodicals is seemingly low, why are the users there?

2. If users do not browse "essential" journals in the library within the first year of receipt, do they browse them at all? Do they have access to these journals elsewhere, e.g., departmental or personal subscriptions? When in the course of a title's life do patrons use it?

3. What bearing do subscription costs have on the use or relevance of titles?

4. Why do some subject areas receive more use among current journals than others?

A recent survey by the Faxon Company found that 80 percent of academic libraries planned to cancel low-use journals during fiscal year $1988-89 .{ }^{20}$ However, the term low-use is not formally defined.

Despite the seemingly inconclusive results of the initial use study conducted at Texas A\&M, the investigators recommend that a more elaborate use study be undertaken before the next cancellation project. To meet these needs, an additional study is in the planning stage to determine the use of current and back issues of titles in all subjects, price ranges, and scores.

\section{REFERENCES}

1. Sherrie Schmidt, Gloriana St. Clair, and Jane Treadwell, "Using dBase III + to Create a Serials Review List," Microcomputers for Information Management: An International Journal for Library and Information Services 5:169-82 (Sept. 1988).

2. Laura Neama, "Periodicals Cancellation: Making a Virtue Out of Necessity," Serials Librarian 10:33-42 (Spring 1986).

3. Barbara A. Rice, "'Science Periodicals Use Study," Serials Librarian 4:35-47 (Fall 1979).

4. Colin R. Taylor, "A Practical Solution to Weeding University Library Periodicals Collections," Collection Management 1:27-45 (Fall-Winter 1976-77).

5. Charles B. Wenger and Judith Childress, "Journal Evaluation in a Large Research Library," Journal of the American Society for Information Science 28:293-99 (Sept. 1977).

6. Maurice B. Line, "Rank Lists Based on Citations and Library Uses as Indicators of Journal Usage in Individual Libraries," Collection Management 2:313-16 (Winter 1978).

7. Johanna Ross, "Research Notes: Observations of Browsing Behavior in an Academic Library," College \& Research Libraries 44:269-76 (July 1983).

8. W. M. Shaw, "A Practical Journal Usage Technique," College \& Research Libraries 39:479-84 (Nov. 1987).

9. Wenger and Childress, "Journal Evaluation," p.296.

10. Taylor, "A Practical Solution to Weeding," p.32.

11. Ibid., p.37.

12. Rice, "Science Periodicals Use Study."

13. Wenger and Childress, "Journal Evaluation," p.294, 298.

14. Neama, "Periodicals Cancellation," p.35-36.

15. Wenger and Childress, "Journal Evaluation," p.294-95.

16. Ross, "Research Notes: Observations of Browsing Behavior."

17. Rice, "Science Periodicals Use Study," p.36.

18. Taylor, "A Practical Solution to Weeding," p.32.

19. Ross, "Research Notes: Observations of Browsing Behavior."

20. Faxon Collection Development Series: Library Profiles \#1 (Faxon Press, 1988). 


\section{Join}

\section{The}

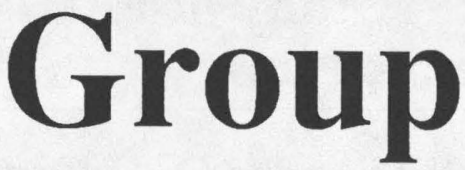

Add your school to the growing list of more than 100 major institutions that now belong to Wisc-Ware, a primary distributor of the latest research and instructional software available for MS DOS-based microcomputers. Through Wisc-Ware, your faculty can both locate and distribute software in almost every field of study.

Campus, Individual and Class License options exist for your institution. A demonstration center with more than 200 products is also available for your library or micro lab. More than half the Wisc-Ware products run under windows.

\section{Call 800-543-3201}

For a FREE Membership Guide Wisc-Ware

University of Wisconsin-Madison Bitnet:wiscware@wiscmacc

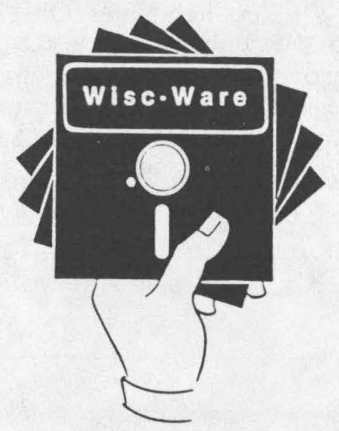

